\title{
Wider den Sittenzerfall
}

Es wird Sie vielleicht erstaunen, dass wir den Leserbrief auf Seite 1965 veröffentlichen. Es sollte Sie sogar schockieren, denn dieser Brief ist anonym, beleidigend und obszön und erfüllt damit alle Kriterien einer Ablehnung. Dass wir eine solche Schreibe veröffentlichen, hat dennoch seinen guten Grund.

Diesen, von einem unbekannten Absender an die persönliche Adresse des FMH-Präsidenten gerichteten Brief müsste man ohne auch nur einen Gedanken darüber zu verschwenden geradewegs dem Papierkorb anvertrauen. Bedauerlicherweise handelt es sich aber hier nicht um einen Einzelfall. Dieser Brief trägt eine Handschrift, eine Handschrift, die in der täglichen Korrespondenz unseres Präsidenten immer wieder vorkommt und die unverwechselbar ist: Es ist die Handschrift eines dieser immer zahlreicheren Kollegen, die sich in ihren standespolitischen Äusserungen keines Anstandes mehr verpflichtet fühlen. Ob Sie's glauben oder nicht, viele dieser Zuschriften werden tatsächlich mit vollem Namen unterschrieben, und diese Namen schmückt fast ausnahmslos ein akademischer Titel: «Dr. med.». Und in diesen Zuschriften strotzt es von Beschimpfungen und Beleidigungen, selbst vor Drohungen wird nicht haltgemacht. Wer allerdings viel mit Kollegen zu korrespondieren hat, wird das etwas weniger erstaunen. Es herrscht allgemein der Eindruck, dass im sogenannten interkollegialen Umgang die Sitten verrohen. Ein aggressiver Tonfall in den E-Mails, Drohungen per Fax, Beschimpfungen am Telefon sind fast schon zur Gewohnheit geworden. Dieser Entwicklung, die wir auch in der Redaktion hautnah mitverfolgen dürfen, gilt es Einhalt zu gebieten, denn das Mass ist voll.

Jeder Kreuzzug wider den Sittenzerfall sollte mit einer «Kehrete» vor der eigenen Haustür beginnen. Dass gerade die Schweizerische Ärztezeitung mit der Publikation von hemdsärmeligen oder holzschnitzartigen Beiträgen zu diesem aggressiven Klima beigetragen hat, ist zugegebenermassen nicht von der Hand zu weisen. Im Rückblick kann man sicher diesen oder jenen Beitrag ausfindig machen, der nur auf üble Stimmungsmache abzielte und auf deren Publikation man problemlos hätte verzichten können. Im nachhinein ist man eben immer schlauer. Aller- dings gilt es, einen feinen, aber bedeutenden Unterschied zu beachten: es ist der Unterschied, ob sich ein Beitrag gegen eine Sache oder gegen eine Person richtet. Wenn es um die Sache geht, ist es manchmal sogar wünschenswert, dass die Auseinandersetzung mit allem Gewicht der Überzeugungen und mit aller Schärfe der Argumente ausgefochten wird. Darauf zu verzichten, könnte sogar einen empfindlichen Verlust an Freiheit bedeuten, nebenbei bemerkt einen letzten Rest an Freiheit, den diese Ärzteschaft noch hat und nicht auch noch preisgeben sollte. Niemals aber darf die Grenze überschritten werden, von welcher an «auf den Mann» gespielt wird. Man kann selbst dann noch Verständnis aufbringen, wenn ein Kollege einmal den Ärger rauslassen muss, das kann jedem von uns passieren, das darf auch sein und sollte nicht überbewertet werden. Die gegenwärtige Entwicklung hat aber auch damit nichts mehr zu tun, denn sie hat epidemischen Charakter, umfasst breite Anteile der Ärzteschaft und vergiftet die gesamte Atmosphäre des persönlichen Umgangs. Diese Entwicklung darf definitiv nicht mehr hingenommen werden.

Letztlich geht es nicht nur um den interkollegialen Umgang, sondern auch um das Bild, welches die Ärzteschaft nach aussen vermittelt. Es wäre naiv zu glauben, dass diese internen Querelen von Aussenstehenden nicht wahrgenommen würden. Vorkehrungen, einen verschwiegenen innerärztlichen Diskurs zu führen, wirken da nur noch lächerlich, denn längst haben Transparenzansprüche und Kommunikationsmittel auch unseren Berufsstand zum gläsernen Objekt gemacht. Um also unsere Denk- und Redefreiheit zu erhalten und zu fördern, ist es dringend angezeigt, in den standespolitischen Diskussionen wieder zu den allgemein gültigen Regeln der Vernunft und des Anstands zurückzukehren. Jeder von uns kann aktiv daran beitragen. Nicht zuletzt damit, dass anonyme, beleidigende und obszöne Zuschriften nicht mehr beantwortet werden. Dieser Brief ist jedenfalls der letzte dieser Art, den die SÄZ auf Seite 1965 publizieren wird.

Dr. med. Markus Trutmann, Chefredaktor 